\title{
CARACTERÍSTICAS DE SILAGENS DE MILHO INOCULADAS COM LACTOBACILLUS BUCHNERI E L. PLANTARUM
}

\author{
CHARACTERISTICS OF CORN SILAGES INOCULATED WITH \\ LACTOBACILLUS BUCHNERI AND L. PLANTARUM
}

\author{
Salvo, P.A.R. ${ }^{1}$; Basso, F.C. ${ }^{*}$; Rabelo, C.H.S. ${ }^{1}$; Oliveira, A.A. ${ }^{1}$; Sader, A.P. ${ }^{1}$; \\ Casagrande, D.R. ${ }^{2}$; Berchielli, T.T. ${ }^{1}$ e Reis, R.A. ${ }^{1}$
}

${ }^{1}$ Faculdade de Ciências Agrárias e Veterinárias. Universidade Estadual Paulista Júlio de Mesquita Filho (UNESP). Jaboticabal, SP. Brasil. *fcarvalhobasso@yahoo.com.br

'Departamento de Zootecnia. Universidade Federal de Lavras (UFLA). Lavras, MG. Brasil.

\section{PalaVRas ChaVe adicionais}

Ácidos orgânicos. Consumo. Digestibilidade. Estabilidade aeróbia. Valor nutritivo.

\section{RESUMO}

Objetivou-se avaliar o padrão fermentativo, estabilidade aeróbia e valor alimentício de silagens de milho inoculadas com Lactobacillus buchneri associado ou não ao L. plantarum. Os tratamentos avaliados foram: silagem de milho sem inoculação (controle); silagem de milho inoculada com $L$. buchneri NCIMB 40788 (1×105 UFC/g forragem); silagem de milho inoculada com L. buchneriNCIMB 40788 e L. plantarum MA18/5U ( $1 \times 10^{5} \mathrm{UFC} / \mathrm{g}$ forragem). A inoculação com L. buchneripromoveu alterações no padrão fermentativo e composição química das silagens, notando-se maior perda de matéria seca (MS) e estabilidade aeróbia nestas silagens. Contudo, as mudanças químicas ocorridas durante a fermentação não foram suficientes para alterar o consumo de MS e de nutrientes por novilhas mestiças, embora tenha se observado maiores digestibilidade da MS e matéria orgânica devido à ação das bactérias ácidoláticas, o que refletiu na maior produção de ácidos graxos de cadeia curta e menores valores de $\mathrm{pH}$. Os resultados deste trabalho permitem concluir que a estabilidade aeróbia das silagens de milho aumenta devido à aplicação de $L$. buchneri de forma isolada. Contudo, a aplicação isolada ou associada ao $L$. plantarum não altera o consumo de matéria seca e de nutrientes, mas resulta no aumento da digestibilidade aparente da matéria seca e matéria orgânica.

\section{AdDiTIONAL KEYWORDS}

Aerobic stability. Digestibility. Intake. Nutritive value. Organic acids.

\section{SUMMARY}

The aim of this research was to evaluate the fermentation, aerobic stability and nutritional value of corn silages inoculated with Lactobacillus buchneri combined or not with Lactobacillus plantarum. The treatments evaluated were: corn silage untreated (control); corn silage inoculated with Lactobacillus buchneri strain NCIMB 40788 ( $1 \times 10^{5} \mathrm{cfu} / \mathrm{g}$ forage); corn silage inoculated with Lactobacillus buchneristrain NCIMB 40788 ( $1 \times 10^{5}$ $\mathrm{cfu} / \mathrm{g}$ forage) and Lactobacillus plantarum strain MA18/5U ( $1 \times 10^{5} \mathrm{cfu} / \mathrm{g}$ forage). The inoculation with Lactobacillus buchneri promoted changes in fermentation and chemical composition of silages and, there was higher dry matter (DM) loss and aerobic stability in these silages. However, the changes occurred during the fermentation were not enough to change the DM and nutrient intake of the heifers, although there was higher DM and organic matter digestibility due to action of the lactic acid bacteria. These facts resulted in an increase of short-chain fatty acids production and a decrease in the $\mathrm{pH}$ values. The results of this study showed that the aerobic stability of corn silages is improved after inoculation with Lactobacillus buchneri. However, the alone or combined application with Lactobacillus plantarum do not change the dry matter and nutrient intake, but dry matter and organic matter apparent digestibility is enhanced. 


\section{INTRODUÇÃO}

Os alimentos utilizados na nutrição animal devem ser de alto valor nutritivo, principalmente para animais de alta produção. Neste aspecto, a silagem de milho é amplamente utilizada pelos produtores, notadamente os de leites, pois atende em grande parte as exigências nutricionais dos animais.

A planta de milho apresenta características desejáveis ao processo de ensilagem, entretanto, após a abertura dos silos, a silagem torna-se susceptível à deterioração pela presença de ácido lático e alta concentração de nutrientes, os quais são utilizados como substrato para o desenvolvimento, principalmente, de leveduras e fungos filamentosos, causando a deterioração da silagem, o que afeta o consumo e desempenho animal. Portanto, pesquisas têm sido desenvolvidas para buscar formas de sanar este problema por meio da inoculação de bactérias ácido-láticas heterofermentativas no momento da ensilagem, pois estes microrganismos apresentam algumas vantagens em relação aos demais aditivos por serem fáceis de utilizar, não corroerem o maquinário e não poluírem o ambiente (Contreras-Gouvea e Muck, 2006).

O controle da deterioração ocorre pela maior concentração de ácido acético, produzido a partir da fermentação dos carboidratos solúveis, o qual possui efeito antifúngico. Todavia, durante a fase fermentativa há maior perda de matéria seca (MS) quando se utiliza bactérias heterofermentativas obrigatórias, pela produção de ácido lático e acético, entre outros e dióxido de carbono e água. Desta forma, uma alternativa para controlar as perdas seria a combinação de bactérias heterofermentativas e homofermentativas, uma vez que a ação das bactérias homofermentativas resulta em silagem bem preservada pela maior produção de ácido lático (Kung Jr. e Ranjit, 2001; Muck, 2010). Contudo, esta estratégia de manipulação do processo fermentativo pode afetar negativamente o consumo de matéria seca e de nutrientes pelos animais (Kung Jr. et al., 2003a).

No entanto, de acordo com Weinberg et al. (2004), um fator positivo que poderia beneficiar os animais alimentados com silagens inoculadas, seria um possível aumento no ganho de peso, devido à melhora na digestão da fibra por uma interação entre microrganismos da silagem e do rúmen, ou até mesmo por um efeito probiótico do inoculante. A melhora na digestão da fibra ocorre, possivelmente pela produção de ferulato-esterase pelo L. buchneri (Kung Jr., 2009), a qual aumenta a digestão da fração fibrosa da silagem.

Contudo, Muck (2010) salienta que os mecanismos que interferem na ação das bactérias ácido-láticas sobre o desempenho animal ainda não estão totalmente claros, sendo necessária a realização de novas pesquisas. Portanto, este estudo foi conduzido com o objetivo de avaliar a estabilidade aeróbia e valor alimentício em novilhas mestiças leiteiras de silagens de milho inoculadas com Lactobacillus buchneri isolado ou associado ao $L$. plantarum.

\section{MATERIALEMÉTODOS}

O experimento foi conduzido no setor de Forragicultura da Faculdade de Ciências Agrárias e Veterinárias (FCAV) da Universidade Estadual Paulista (UNESP), campus de Jaboticabal - SP. Utilizou-se no estudo o híbrido de milho Maximus (Syngenta), colhido por uma máquina forrageira (Menta) regulada para altura de corte de $20 \mathrm{~cm}$ e tamanho de partículas de $0,5 \mathrm{~cm}$. No momento da colheita, os grãos apresentavam de um a dois terços da linha do leite, o que correspondeu a faixa de 30 a $35 \%$ de matéria seca (MS).

Avaliaram-se os seguintes tratamentos: silagem de milho sem inoculante (controle); silagem de milho inoculada com Lactobacillus buchneri NCIMB 40788 (1x1055FC/g 
forragem); silagem de milho inoculada com L. buchneri NCIMB $40788\left(1 \times 10^{5} \mathrm{UFC} / \mathrm{g}\right.$ forragem) e L. plantarum MA18/5U (1x10 $\mathrm{UFC} / \mathrm{g}$ forragem). Os inoculantes foram diluídos em água destilada e aplicados com pulverizador manual costal (Jacto) na forragem durante o enchimento dos silos, mantendo-se a relação de $2 \mathrm{~mL}$ da solução por quilo de forragem fresca. No tratamento controle, aplicou-se a mesma quantidade de água. Foram confeccionados três silos tipo superfície com aproximadamente 10 toneladas de forragem cada. Amostras de forragem foram coletadas para caracterizar a planta de milho no momento da ensilagem (tabela I).

Os silos foram abertos após 165 dias de ensilagem. As perdas quantitativas de matéria seca foram avaliadas somente na região periférica dos silos, colocando-se seis sacos de ráfia, denominados de sacos traçadores (pareados dois a dois) com $5 \mathrm{~kg}$ de forragem em cada, enterrados a $10 \mathrm{~cm} \mathrm{da}$ superfície. Os sacos traçadores foram pesados durante o enchimento dos silos e após a abertura, conforme retirada da silagem, determinando-se os teores de matéria seca para quantificação das perdas (McDonald etal., 1991).

Durante o desabastecimento dos silos, os sacos traçadores foram localizados e recolhidos. Parte da amostra retirada de dentro dos sacos foi destinada à determinação dos valores de $\mathrm{pH}$ em extrato aquoso elaborado a partir de um material fresco (Kung Jr. et al., 1984) e nitrogênio amoniacal - N-NH (AOAC, 1996). As análises microbiológicas das silagens foram realizadas pesando-se $25 \mathrm{~g}$ de silagem (matéria natural) e adicionando-se $225 \mathrm{~mL}$ de solução peptonada a $0,1 \%(0,1 \mathrm{~g}$ de peptona por litro de água destilada). Após agitação das amostras, retirou-se $1 \mathrm{~mL}$ da diluição para posteriores diluições de $10^{-2}$ a $10^{-5} \mathrm{e}$, a partir dessas diluições, foram realizadas as semeaduras de $0,1 \mathrm{~mL}$ em placas de Petri contendo o meio ágar batata acidificado (Difco), onde foram incubadas em aerobiose por 72 horas a $28^{\circ} \mathrm{C}$ para contagem das colônias de leveduras e por 120 horas para a contagem dos fungos filamentosos (Jobim et al., 1999).

Para avaliação da estabilidade aeróbia das silagens, cerca de três quilos de silagens foram retiradas de cada saco traçador foram colocadas em baldes com capacidade de $7 \mathrm{~L}$, permanecendo em uma sala fechada, por 5 dias em temperatura ambiente para avaliação. A temperatura das silagens foi registrada a cada meia hora por um data logger inserido no centro da massa e a temperatura ambiente foi medida por data loggers distribuídos próximos aos baldes. Segundo Jobim et al. (2007), a condução do ensaio de estabilidade aeróbia em temperatura ambiente apresenta

Tabela I. Composição bromatológica (\% na matéria seca), valores de $\mathrm{pH}$, nitrogênio amoniacal em relação ao nitrogênio total $\left(\mathrm{NH}_{3} / \mathrm{NT}\right)$ e contagem de leveduras da planta de milho após aplicação dos inoculantes no momento da ensilagem. (Chemical composition (\% of dry matter), $\mathrm{pH}$ values, ammonia $\mathrm{N}$ in relation total nitrogen $\left(\mathrm{NH}_{3} / \mathrm{NT}\right)$ and yeasts occurrence of corn plant after inoculants application in the ensiling moment).

\begin{tabular}{lccc}
\hline & $\mathrm{C}$ & LB & LB+LP \\
\hline $\mathrm{MS}$ & 32,02 & 35,48 & 31,42 \\
$\mathrm{MM}$ & 4,83 & 5,12 & 5,26 \\
$\mathrm{~PB}$ & 8,73 & 8,01 & 8,85 \\
$\mathrm{EE}$ & 2,68 & 2,62 & 2,73 \\
$\mathrm{FDN}$ & 58,04 & 56,92 & 58,73 \\
$\mathrm{FDA}$ & 27,15 & 26,08 & 28,41 \\
Hemicelulose & 30,89 & 30,84 & 30,32 \\
Celulose & 21,86 & 21,94 & 20,48 \\
Lignina & 5,44 & 4,17 & 5,90 \\
pH & 5,14 & 5,17 & 5,33 \\
$\mathrm{NH}_{3}$ NT & 2,31 & 2,38 & 2,27 \\
Leveduras $^{*}$ & 6,34 & 6,32 & 6,21 \\
\hline
\end{tabular}

$\mathrm{LB}=\mathrm{L}$. buchneri; $\mathrm{LP}=\mathrm{L}$. plantarum.

$\mathrm{C}=$ controle $\mathrm{MS}=$ matéria seca; $\mathrm{MM}=$ matéria mineral; $\mathrm{PB}=$ proteína bruta; $\mathrm{EE}=$ extrato etéreo; $\mathrm{FDN}=$ fibra em detergente neutro; FDA= fibra em detergente ácido.

${ }^{*} \log _{10}$ UFC/g. 


\section{SALVO, BASSO, RABELO, OLIVEIRA, SADER, CASAGRANDE, BERCHIELLI E REIS}

alta acurácia na estimativa da velocidade de deterioração da silagem em situação de campo. A quebra da estabilidade aeróbia foi definida como o tempo necessário para que a silagem ultrapassasse a temperatura ambiente em $2{ }^{\circ} \mathrm{C}$ (Kung Jr. et al., 2003b).

No intuito de investigar os efeitos das bactérias ácido-láticas (BAL) aplicadas na planta de milho sobre o consumo, os produtos finais da digestão e a digestibilidade, foram utilizadas 3 novilhas mestiças leiteiras, canuladas no rúmen, com peso corporal médio de $368 \mathrm{~kg}$.

Os animais foram alojados em baias individuais, equipadas com comedouros e bebedouros, permanecendo em adaptação às dietas e ao ambiente por 14 dias, com início do experimento após este período. A fase experimental foi constituída de três períodos de 10 dias, sendo que em cada período 7 dias foram destinados a adaptação a dieta e 3 dias de colheita de amostras de fornecido, sobras e fezes, que foram agrupadas para cada animal por período.

Os animais foram alimentados uma vez ao dia às 7:00 horas, permitindo consumo ad libitum (quantidade de sobras próxima a $10 \%$ da quantidade fornecida). A quantidade de alimento fornecido e das sobras foi registrada diariamente, para cálculo do consumo. A dieta foi formulada mantendo-se a relação volumoso:concentrado de 80:20_em todos os tratamentos, sendo compostas por $80 \%$ de silagem de milho, $17,4 \%$ de milho moído, 1,6\% de farelo de soja e 1,0\% de núcleo mineral. As dietas foram balanceadas de acordo com as recomendações descritas pelo NRC (2001) para ganhos de $500 \mathrm{~g} /$ dia em novilhas mestiças com peso médio de $350 \mathrm{~kg}$, sendo isoprotéicas e isoenergéticas (tabela II).

Amostras de silagem, concentrado e de sobras foram colhidas para análise laboratorial, sendo estas acondicionadas em sacos plásticos e armazenadas em freezer ( -20 ${ }^{\circ} \mathrm{C}$ ). Posteriormente foram pré-secas em estufa ventilada a $55^{\circ} \mathrm{C}$ até atingirem peso constante (72 horas) e moídas em moinho tipo Willye, utilizando-se peneira com crivos de $1 \mathrm{~mm}$. O teor de matéria seca (MS) não foi corrigido para perdas de compostos voláteis, como os ácidos orgânicos. Os teores de MS foram determinados em estufa à $105^{\circ} \mathrm{C}$ por 12 horas e os de matéria mineral (MM) em mufla à $500^{\circ} \mathrm{C}$ por 5 horas. As concentrações de matéria orgânica (MO) foram calculadas $(\mathrm{MO}=100-\mathrm{MM})$. Os teores de nitrogênio total (NT) e extrato etéreo (EE) foram determinados de acordo com AOAC (1996), sendo a proteína bruta $(\mathrm{PB})$ obtida pelo produto entre o nitrogênio total e o fator 6,25 . Os teores de fibra em detergente neutro (FDN) e fibra em detergente ácido (FDA) foram avaliados segundo as técnicas descritas por Van Soest et al. (1991). Nas análises de FDN, estes valores foram corrigidos para cinzas e proteína (FDNcp). A lignina foi determinada após a solubilização da celulose em ácido sulfúrico a 72 \% (Van Soest, 1994). Os carboidratos totais (CHOT) e carboi-

Tabela II. Composição bromatológica (\% na MS) das dietas utilizadas na alimentação das novilhas mestiças. (Bromatologic composition (\% of DM) of diets used in the feeding of heifers).

\begin{tabular}{lccc}
\hline Item & Controle & LB & LB+LP \\
\hline MS & 43,48 & 44,88 & 42,05 \\
MM & 3,82 & 4,41 & 4,41 \\
MO & 96,18 & 95,59 & 95,59 \\
PB & 10,31 & 10,83 & 10,30 \\
EE & 2,95 & 3,04 & 3,02 \\
FDN & 42,11 & 42,13 & 42,63 \\
FDA & 24,04 & 23,36 & 24,37 \\
CHOT & 84,08 & 82,89 & 83,42 \\
CNF & 38,41 & 37,70 & 37,59 \\
NDT & 61,24 & 61,80 & 61,22 \\
\hline
\end{tabular}

$\mathrm{LB}=$ L. buchneri; $\mathrm{LP}=$ L. plantarum.

$\mathrm{MS}=$ matéria seca; $\mathrm{MM}=$ matéria mineral; $\mathrm{MO}=$ matéria orgânica; $\mathrm{PB}=$ proteína bruta; $\mathrm{EE}=$ extrato etéreo; FDN= fibra em detergente neutro; FDA= fibra em detergente ácido; $\mathrm{CHOT}=$ carboidratos totais; CNF= carboidratos não fibrosos; NDT= nutrientes digestíveis totais. 
dratos não fibrosos (CNF) foram calculados de acordo com as equações:

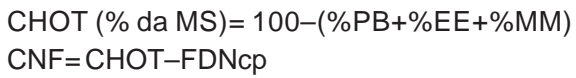

propostas por Sniffen et al. (1992), e os nutrientes digestíveis totais (NDT) calculados:

$\operatorname{NDT}(\%)=P B d+\left(A G d^{*} 2,25\right)+F D N p d+C N F d$

Em que os valores de proteína bruta digestível (PBd), ácidos graxos digestíveis (AGd), FDN digestível corrigida para proteína (FDNpd) e carboidratos não fibrosos digestíveis (CNFd) foram estimados conforme as equações:

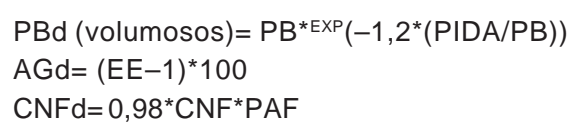

$\mathrm{PAF}=$ fator de ajuste para processamento físico.

FDNpd $=0,75(\text { FDNp-lignina })^{*}[1-($ lignina $/$ FDNp) $\left.)^{0,667}\right]$

As digestibilidades verdadeiras da PB, AG e CNF foram corrigidas para excreção fecal metabólica de cada nutriente, de acordo com o NRC (2001). Dessa forma, os valores estimados a partir das equações citadas acima foram subtraídos em 2,7; 1,4 e 3,1 unidades percentuais para a PBd, AGd e CNFd, respectivamente.

Os ácidos orgânicos voláteis presentes nas silagens foram determinados segundo a metodologia descrita por Wilson (1971), utilizando-se cromatógrafo a gás (HP 4890), e o ácido lático foi quantificado conforme Barker e Summerson (1941).

As fezes foram colhidas parcialmente, diretamente do reto dos animais uma vez ao dia, durante três dias consecutivos de colheita, nos respectivos horários 8:00; 12:00 e 18:00 horas, sendo acondicionadas em sacos plásticos e armazenadas em freezer.
As fezes foram pré-secas em estufa de ventilação forçada a $55^{\circ} \mathrm{C}$ até peso constante. Amostras individuais dos animais foram homogeneizadas para obtenção de amostras compostas por período, determinando-se os teores de MS, MM, MO, PB, EE, FDN, FDNcp, CHOT e CNF de acordo com as metodologias descritas anteriormente. A produção fecal total foi determinada utilizando-se o indicador interno fibra em detergente ácido indigestível (FDAi), incubado in situ por 264 horas (Casali et al., 2008). A digestibilidade aparente total dos nutrientes foi obtida pela diferença entre o consumido e o excretado.

No último dia de cada período experimental, realizaram-se colheitas de líquido ruminal nos tempos $0,3,6,9$ e 12 horas após o fornecimento do alimento. Imediatamente após a colheita, os valores de $\mathrm{pH}$ foram determinados por meio da leitura de aproximadamente $50 \mathrm{~mL}$ de fluido ruminal utilizando-se peagâmetro digital. Em seguida, as amostras foram colocadas em potes plásti$\cos$ contendo $1 \mathrm{~mL}$ de solução de ácido sulfúrico a $50 \%$ e congeladas para análise da concentração ruminal de $\mathrm{N}-\mathrm{NH}_{3}$ e ácidos graxos de cadeia curta. Determinou-se a concentração de $\mathrm{N}-\mathrm{NH}_{3}$ mediante destilação com KOH 2N (Fenner, 1965). Os ácidos graxos de cadeia curta presentes no líquido ruminal foram determinados segundo a metodologia descrita por Famme e Knudsen (1984).

A análise estatística para avaliar as perdas fermentativas na região superficial dos silos foi realizada utilizando um modelo misto por meio do procedimento MIXED do programa SAS, versão 9.0 (SAS, 2008). Primeiramente, foi escolhida a melhor estrutura de covariância utilizando-se como critério o BIC (Schwarz's Bayesian Criterion). Os efeitos principais de silagem foram analisados pelo teste de $\mathrm{T}$ a $5 \%$ de probabilidade. As interações entre os fatores estudados foram divididas usando a opção SLICE do SAS, sendo a retirada dos sacos o fator de divisão. 


\section{SALVO, BASSO, RABELO, OLIVEIRA, SADER, CASAGRANDE, BERCHIELLI E REIS}

Na condução do experimento envolvendo os animais, utilizou-se o delineamento em quadrado latino $3 \times 3$, repetido no tempo, composto por 3 animais, 3 tratamentos e 3 períodos. Os dados obtidos foram submetidos à análise de variância e as médias dos tratamentos comparadas pelo teste $\mathrm{T}$ a $5 \%$ de significância por meio do software SAS.

\section{RESULTADOSEDISCUSSÃO}

Os valores de $\mathrm{pH}$ e $\mathrm{NH}_{3} / \mathrm{NT}$ avaliados nas amostras colhidas nos sacos traçadores localizados na superfície dos silos não foram alterados pela inoculação das bactérias ácidos láticas (BAL), contudo, diferentes concentrações de ácido acético foram observadas (tabela III). Embora os valores de pH não tenham modificado devido à ação das BAL, estes ficaram dentro da faixa considerada ideal para silagem de milho $(3,8 \mathrm{a} 4,2)$. Entretanto, a concentração de $\mathrm{NH}_{3} / \mathrm{NT}$ em torno de $7 \%$ em todas as silagens, pode ser indicativo de atividade de bactérias do gênero Clostridium, devido ser o material mais exposto as trocas gasosas e ter alta atividade de microrganismos, pode haver nichos anaeróbios que possibilitam a multiplicação dessas bactérias.

A inoculação das silagens com a combinação das BAL promoveu acréscimo na concentração do ácido acético, o que está de acordo com os resultados observados por outros pesquisadores que utilizaram BAL heterofermentativas e homofermentativas associadas (Filya, 2003; Filya et al., 2006; Kleinschmit et al., 2005). Isto ocorre devido ao L. buchneri converter hexoses em ácido lático, ácido acético, $\mathrm{CO}_{2}$ e água (McDonald et al., 1991). A vantagem associada ao acréscimo na concentração de ácido acético está no controle do desenvolvimento de microrganismos, principalmente leveduras, durante a fase fermentativa e após a abertura do silo (tabela III). Segundo Driehuis et al. (1999), as leveduras são afetadas de duas maneiras pela inoculação de L. buchneri na massa ensilada. Uma é a redução na sobrevivência destes microrganismos durante o processo fermentativo e, a segunda ocorre durante a fase aeróbia, havendo inibição no crescimento destes microrganismos. Danner et al. (2003) reportaram que a correlação entre a concentração de ácido acético e estabilidade aeróbia é alta $(0,95)$. Além da produção de ácido acético e 1,2 propanodiol pelo $L$. buchneri, esta bactéria também produz outras substâncias antimicrobianas que são responsáveis por aumentar a estabilidade aeróbia, como a buchnericina, que age contra uma gama de microrganismos em ampla faixa de pH (2 a 9) (Yildirim, 2001). Desta forma, notou-se tendência de melhora_na estabilidade na silagem inoculada com $L$. buchneri de no mínimo 11,4 horas em relação às demais silagens (tabela III).

Todavia, a inoculação da forragem com L. buchneri e/ou L. plantarum resultou em maiores perdas de MS nos sacos traçadores removidos dos silos em outubro e novembro comparada a controle (tabela III), o que é devido a maior produção de $\mathrm{CO}_{2}$ pela $L$. buchneri (Oude Elferink et al., 2001), pois esta possui a enzima carboxilase necessária para retirada das moléculas de $\mathrm{CO}_{2}$ do ácido pirúvico (Butler e Bailey, 1973).

Avaliou-se a ocorrência de microrganismos, perdas de MS e estabilidade aeróbia das silagens tomando por base a massa presente na superfície dos silos (sacos traçadores), pois de acordo com Ashbell e Weinberg (1992), a massa presente neste local apresenta maior susceptibilidade à ação de microrganismos. Isto ocorre devido a maior troca gasosa oriunda da porosidade presente em materiais de vedação à base de polietileno (Borreani et al., 2007), que geralmente são os mais comuns em propriedades rurais.

$\mathrm{Na}$ avaliação da silagem fornecida aos animais, verificou-se maior produção de ácido lático naquela inoculada com a combinação das BAL em relação àquela inoculada somente com L. buchneri (tabela IV), o que era esperado, pois o L. plantarum metaboliza açúcares solúveis em ácido lático 
INOCULAÇÃO DE SILAGENS DE MILHO COM LACTOBACILLUS

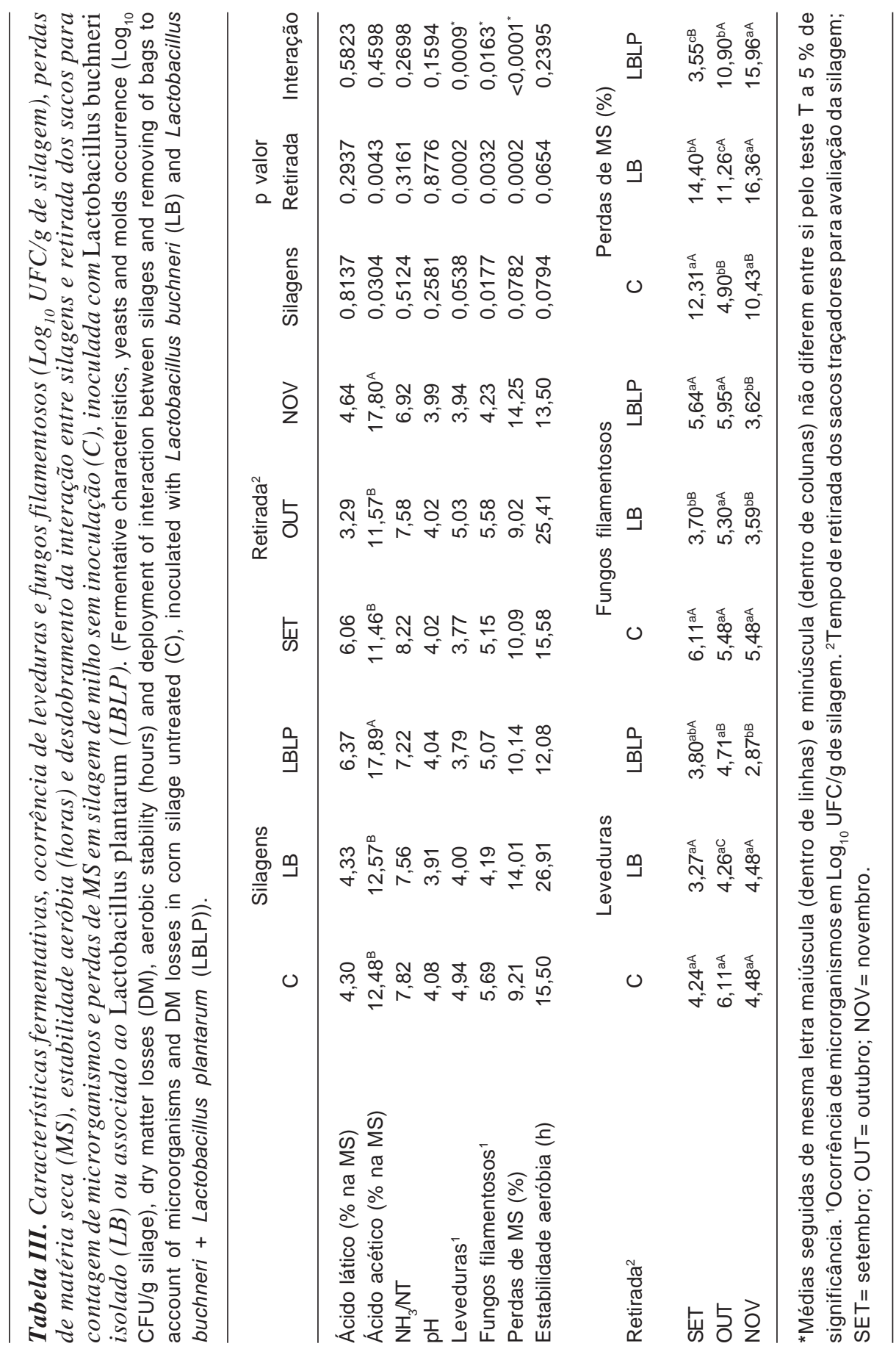

Archivos de zootecnia vol. 62, núm. 239, p. 385. 


\section{SALVO, BASSO, RABELO, OLIVEIRA, SADER, CASAGRANDE, BERCHIELLI E REIS}

como produto final. Quanto à produção de ácido acético, notou-se maior concentração na silagem inoculada com L. buchneri $+L$. plantarum comparado à silagem controle. A concentração de $\mathrm{N}-\mathrm{NH}_{3}$ foi semelhante entre as silagens. Todas silagens apresentaram concentração de $\mathrm{N}-\mathrm{NH}_{3}$ abaixo da faixa estabelecida por Kung Jr. e Shaver (2001), situada entre 5 e $7 \%$, como limite para esta variável.

Tabela IV. Características fermentativas e bromatológicas das silagens de milho inoculadas ou não com Lactobacillus buchneri $(L B) e$ L. buchneri $+\mathrm{L}$. plantarum $(L B L P)$ fornecidas aos animais. (Fermentative and bromatologic characteristics of corn silages inoculated or not with Lactobacillus buchneri (LB) and L. buchneri + L. plantarum (LBLP) provided to animals).

\begin{tabular}{|c|c|c|c|c|c|}
\hline & Controle & $\begin{array}{c}\text { Silagens } \\
\text { LB }\end{array}$ & LBLP & $\mathrm{P}$ valor & CV (\%) \\
\hline Ácido lático (\% na MS) & $6,73^{\mathrm{AB}}$ & $6,23^{\mathrm{B}}$ & $9,28^{A}$ & 0,0185 & 15,66 \\
\hline Ácido acético (\% na MS) & $2,71^{B}$ & $4,15^{\mathrm{AB}}$ & $5,54^{\mathrm{A}}$ & 0,0048 & 26,82 \\
\hline $\mathrm{pH}$ & 4,12 & 4,03 & 4,06 & 0,1975 & 2,70 \\
\hline $\mathrm{NH}_{3} / \mathrm{NT}$ & 2,59 & 2,37 & 2,93 & 0,0757 & 18,89 \\
\hline MS (\%) & $31,68^{\mathrm{AB}}$ & $33,42^{A}$ & $29,88^{B}$ & 0,0022 & 5,93 \\
\hline MO (\% na MS) & $96,57^{A}$ & $95,82^{\mathrm{B}}$ & $95,62^{\mathrm{B}}$ & 0,0001 & 0,42 \\
\hline MM (\% na MS) & $3,43^{\mathrm{B}}$ & $4,17^{\mathrm{A}}$ & $4,37^{A}$ & 0,0001 & 10,07 \\
\hline PB (\% na MS) & 8,20 & 8,85 & 8,20 & 0,0832 & 8,07 \\
\hline EE (\% na MS) & 2,72 & 2,82 & 2,80 & 0,7587 & 11,09 \\
\hline FDN (\% na MS) & 50,70 & 49,21 & 49,85 & 0,4667 & 5,05 \\
\hline FDNp (\% na MS) & 48,19 & 46,92 & 46,30 & 0,3716 & 6,01 \\
\hline FDNcp (\% na MS) & 46,64 & 45,51 & 45,13 & 0,4582 & 4,08 \\
\hline FDA (\% na MS) & $29,23^{\mathrm{AB}}$ & $27,97^{\mathrm{B}}$ & $29,99^{A}$ & 0,0398 & 5,48 \\
\hline CEL (\% na MS) & 24,15 & 22,95 & 24,95 & 0,0698 & 7,27 \\
\hline HEM (\% na MS) & 21,47 & 21,24 & 19,84 & 0,1912 & 9,49 \\
\hline LIG (\% na MS) & 4,34 & 4,10 & 4,44 & 0,4729 & 13,66 \\
\hline PIDN (\% na PB) & 24,97 & 22,40 & 22,09 & 0,6214 & 29,04 \\
\hline PIDA (\% na MS) & 0,78 & 0,71 & 0,78 & 0,7131 & 28,76 \\
\hline PIDA (\% na PB) & 9,62 & 8,11 & 9,42 & 0,4511 & 29,84 \\
\hline CHOT (\% na MS) & $85,64^{A}$ & $84,15^{\mathrm{B}}$ & $84,62^{\mathrm{AB}}$ & 0,0086 & 1,11 \\
\hline CNF (\% na MS) & 39,35 & 38,63 & 38,49 & 0,5555 & 4,57 \\
\hline CNFd (\% na MS) & 33,14 & 32,48 & 32,36 & 0,5555 & 5,00 \\
\hline PBd (\% na MS) & 4,61 & 5,34 & 4,61 & 0,0647 & 14,83 \\
\hline EEd (\% na MS) & 0,45 & 0,47 & 0,40 & 0,8177 & 56,76 \\
\hline FDNpd (\% na MS) & 26,29 & 25,58 & 25,26 & 0,4604 & 6,87 \\
\hline NDT (\% na MS) & 64,62 & 64,49 & 63,46 & 0,1297 & 1,98 \\
\hline
\end{tabular}

A,BMédias seguidas de mesma letra não diferem entre si pelo teste $T(p>0,05)$. N-NH $/ N T=$ nitrogênio amoniacal em relação ao nitrogênio total; $M S=$ matéria seca; $M O=$ matéria orgânica; $M M=$ matéria mineral; $\mathrm{PB}=$ proteína bruta; $\mathrm{EE}=$ extrato etéreo; $\mathrm{FDN}$ = fibra em detergente neutro; $\mathrm{FDNp}=$ fibra em detergente neutro corrigido para proteína; FDNcp= fibra em detergente neutro corrigido para cinzas e proteína; PIDN= proteína insolúvel em detergente neutro; FDA= fibra em detergente ácido; PIDA= proteína insolúvel em detergente ácido; $\mathrm{CEL}=$ celulose; $\mathrm{HEM}=$ hemicelulose; $\mathrm{LIG}=$ lignina; $\mathrm{CHOT}=$ carboidratos totais; $\mathrm{CNF}=$ carboidratos não fibrosos; CNFd= carboidratos não fibrosos digestíveis; $\mathrm{PBd}=$ proteína bruta digestível; $\mathrm{EEd}=$ extrato etéreo digestível; FDNpd= fibra em detergente neutro corrigido para proteína digestível; NDT = nutrientes digestíveis totais (NRC, 2001). 
A inoculação das silagens de milho com L. buchneri associado ou não ao $L$. plantarum resultou na alteração dos teores de MS, MO, MM, FDA e CHOT, entretanto, as demais variáveis não foram afetadas (tabela IV). Verificou-se maior teor de MS na silagem inoculada com L. buchneri em relação à silagem inoculada com L. buchneri e L. plantarum, com valor intermediário na silagem controle. Possivelmente este fato está mais correlacionado com os diferentes teores de MS observados no momento da ensilagem do que propriamente à ação das BAL.

Ao estudar a composição bromatológica, a inoculação das BAL resultou em menores teores de $\mathrm{MO}$ e maiores concentrações de cinzas, ao passo que os teores de CHOT foram maiores na silagem controle em relação à silagem inoculada com $L$. buchneri e valor intermediário na silagem inoculada com $L$. buchneri e L. plantarum (tabela IV). Estas diferenças podem estar correlacionadas à maior produção de $\mathrm{CO}_{2}$ durante a fermentação de silagens inoculadas com BAL heterofermentativas (Oude Elferink et al., 2001). Outro ponto de suporte para esta inferência está relacionado ao fato das silagens inoculadas terem apresentado uma redução um pouco mais intensa no teor de MS comparada à forragem que lhes deu origem, evidenciando as perdas de MS e a produção de água que ocorrem durante a fermentação heterolática.

Não houve efeito dos inoculantes sobre o consumo de MS, MO, PB, CHOT, CNF, EE, FDN, FDA e NDT. O fato das novilhas mestiças não apresentarem alteração no consumo de nutrientes, provavelmente está mais relacionado ao consumo de $\mathrm{MS}$, o qual também não foi alterado, pois o consumo de nutrientes tende a acompanhar o mesmo efeito. Segundo Kung Jr. e Muck (1997), a maior concentração de ácido acético na silagem deveria implicar em menor consumo de matéria seca. Muck (2010) salienta que o consumo é suprimido com concentrações acima de 5,0 \%, contudo isto não foi obser- vado neste estudo (tabela V). Portanto, este fato é positivo, pois este ácido age como inibidor de microrganismos aeróbios oportunistas que deterioram a silagem e, desta forma, preserva maior quantidade de nutrientes. Os resultados obtidos neste estudo discordam dos reportados por Kamarloiy e Yansari (2008), cujos autores inocularam a silagem de milho com $L$. plantarum e Propionibacterium acidipropionici e relataram maior consumo de MS nos animais alimentados com esta silagem $(11,040 \mathrm{~kg} / \mathrm{dia})$ em relação à silagem controle $(8,820 \mathrm{~kg} / \mathrm{dia})$.

Embora não tenha sido verificado efeito dos inoculantes sobre o consumo, notouse que a digestibilidade da MS e MO aumentou devido à aplicação dos inoculantes (tabela V). Em trabalho de revisão, Kung Jr. e Muck (1997) verificaram que em 9 de 13 trabalhos conduzidos entre 1990 e 1995 apresentaram melhora na digestão da MS em virtude da utilização das BAL. Estes resultados podem ser devido à produção da enzima ferulato esterase por algumas BAL (Donaghy et al., 1998), que atua sobre a fração arabinoxilanas da parede celular liberando ferulato (Bartolome et al., 1995) e assim, a fração fibrosa da planta pode-se tornar mais susceptível à ação de enzimas fibrolíticas, refletindo na maior digestibilidade da MS, MO e da FDN.

Entretanto, não houve efeito das BAL sobre a digestibilidade da FDN, assim como sobre a digestão da PB, EE, CHOT e CNF. Kamarloiy e Yansari (2008) reportaram acréscimo na digestibilidade de silagens de milho inoculadas em relação a não tratada (sem inoculante) de 4,88; 4,05; 8,06; 4,02 e $16,55 \%$ para as variáveis MS, PB, FDN, CNF e EE, respectivamente. Embora não tenha havido diferença significativa na digestibilidade da FDN, observa-se que a silagem inoculada com L. buchneri $(\mathrm{DFDN}=53,5 \%)$ apresentou 7 pontos percentuais acima da controle (DFDN=46,0\%), sugerindo atuação da enzima ferulato esterase conforme Kung Jr., 2009. 


\section{SALVO, BASSO, RABELO, OLIVEIRA, SADER, CASAGRANDE, BERCHIELLI E REIS}

Tabela V. Consumo de matéria seca e de nutrientes ( $\mathrm{kg} /$ dia), digestibilidade aparente e parâmetros ruminais de novilhas mestiças alimentadas com silagens de milho inoculadas ou não com $\mathrm{L}$. buchneri $(L B) e \mathrm{~L}$. buchneri + L. plantarum $(L B L P)$. (Dry matter and nutrients intake (kg/day), apparent digestibility and ruminal parameters of heifers feed with corn silages inoculated or not with $L$. buchneri (LB) and $L$. buchneri + L. plantarum (LB+LP)).

\begin{tabular}{|c|c|c|c|c|c|}
\hline & \multicolumn{3}{|c|}{ Silagens* } & \multirow[t]{2}{*}{$p$ valor } & \multirow{2}{*}{$\begin{array}{l}\text { CV } \\
(\%)\end{array}$} \\
\hline & controle & LB & $\mathrm{LB}+\mathrm{LP}$ & & \\
\hline \multicolumn{6}{|c|}{ Consumo (kg/dia) } \\
\hline MS & 7,060 & 7,140 & 6,670 & 0,2893 & 7,19 \\
\hline MO & 6,810 & 6,830 & 6,380 & 0,2521 & 7,08 \\
\hline PB & 0,740 & 0,790 & 0,710 & 0,1799 & 8,53 \\
\hline EE & 0,220 & 0,230 & 0,220 & 0,2035 & 3,89 \\
\hline FDN & 2,920 & 2,900 & 2,770 & 0,6690 & 10,73 \\
\hline FDA & 1,500 & 1,370 & 1,400 & 0,7360 & 20,50 \\
\hline $\mathrm{CHOT}$ & 5,950 & 5,900 & 5,550 & 0,2699 & 7,14 \\
\hline CNF & 2,730 & 2,720 & 2,500 & 0,1451 & 7,48 \\
\hline NDT & 4,490 & 4,540 & 3,990 & 0,2378 & 6,97 \\
\hline \multicolumn{6}{|c|}{ Digestibilidade (\%) } \\
\hline MS & $62,86^{\mathrm{B}}$ & $69,77^{\mathrm{A}}$ & $67,76^{A}$ & 0,0143 & 4,26 \\
\hline MO & $68,17^{\mathrm{B}}$ & $70,70^{\mathrm{A}}$ & $71,47^{A}$ & 0,0002 & 0,98 \\
\hline PB & 56,53 & 63,44 & 59,08 & 0,2341 & 10,69 \\
\hline EE & 80,60 & 79,94 & 75,15 & 0,6979 & 15,05 \\
\hline FDN & 46,00 & 53,50 & 48,80 & 0,3447 & 13,49 \\
\hline $\mathrm{CHOT}$ & 71,73 & 75,44 & 70,14 & 0,3084 & 7,76 \\
\hline CNF & 83,30 & 85,78 & 83,37 & 0,7150 & 6,92 \\
\hline \multicolumn{6}{|c|}{ Parâmetros ruminais (ácidos orgânicos) } \\
\hline acético\# & $55,75^{\mathrm{C}}$ & $63,12^{\mathrm{A}}$ & $59,12^{\mathrm{B}}$ & 0,0002 & 2,50 \\
\hline propiônico & o\#11,14 & 12,88 & 13,59 & 0,1404 & 14,76 \\
\hline butírico\# & $4,09^{B}$ & $4,61^{\mathrm{A}}$ & $4,15^{\mathrm{B}}$ & 0,0217 & 5,82 \\
\hline AC:AP & 5,07 & 5,16 & 4,56 & 0,2529 & 12,03 \\
\hline PT AGCC\# & $\# 70,18^{\mathrm{C}}$ & $80,80^{\mathrm{A}}$ & $77,57^{\mathrm{B}}$ & 0,0005 & 2,95 \\
\hline $\mathrm{pH}$ & $6,14^{\mathrm{A}}$ & $6,09^{A B}$ & $6,03^{\mathrm{B}}$ & 0,0252 & 0,86 \\
\hline $\mathrm{N}-\mathrm{NH}_{3}{ }^{\prime \prime}$ & 10,23 & 10,50 & 9,60 & 0,3232 & 8,48 \\
\hline
\end{tabular}

A,BMédias seguidas de mesma letra não diferem entre si pelo teste T a $5 \%$ de significância. MS= matéria seca; $\mathrm{MO}=$ matéria orgânica; $\mathrm{MM}=$ matéria mineral; $\mathrm{PB}=$ proteína bruta; $\mathrm{EE}=$ extrato etéreo; $F D N=$ fibra em detergente neutro; FDA = fibra em detergente ácido; $\mathrm{CHOT}=$ carboidratos totais; $\mathrm{CNF}=$ carboidratos não fibrosos; NDT= nutrientes digestíveis totais (NRC, 2001); AC:AP= acético: butírico; $A G C C=$ ácidos graxos de cadeia curta; $\mathrm{PT}=$ produção total. ${ } \mathrm{mMol} / \mathrm{mL}$; ${ }^{* \#} \mathrm{mg} / \mathrm{dL}$.
Em relação aos parâmetros ruminais, verificou-se efeito das silagens inoculadas sobre as concentrações de ácido acético e butírico, bem como sobre a produção total de ácidos graxos de cadeia curta (AGCC) e valores de $\mathrm{pH}$. Os ácidos orgânicos das silagens tem efeito restrito no $\mathrm{pH}$, pois a fonte de fibra permite o tamponamento (Reis et al., 2008). As maiores concentrações de ácido acético, butírico e AGCC foram observadas quando as novilhas consumiram silagem de milho inoculada com L. buchneri (tabela V). Esta pode ser uma resposta a maior digestibilidade da FDN, resultando em maior produção de acetato.

Verificou-se menor valor de $\mathrm{pH}$ no tratamento que associou $L$. buchneri e $L$. plantarum comparado a silagem controle, notando-se ainda valor intermediário para silagem inoculada somente com L. buchneri (tabela V). Contudo, os valores de $\mathrm{pH}$ encontrados em todos os tratamentos neste trabalho estão próximos ao limite estabelecido por Strobel e Russell (1986), para otimizar a síntese de proteína microbiana (valores de $\mathrm{pH}$ acima de 6), permitindo o melhor aproveitamento do alimento e/ou dieta.

Avaliaram-se ainda a concentração de ácido propiônico, relação ácido acético: propiônico e nitrogênio amoniacal $\left(\mathrm{N}-\mathrm{NH}_{3}\right)$. No entanto, estes não foram alterados pela aplicação dos inoculantes. Segundo Detmann et al. (2010), um mínimo de $8 \mathrm{mg} /$ $\mathrm{dL}$ de $\mathrm{N}-\mathrm{NH}_{3}$ deve ser estabelecido para garantir a capacidade dos microrganismos fibrolíticos atuar na degradação dos componentes fibrosos. Entretanto, Leng (1990) preconiza valores próximos a $20 \mathrm{mg} / \mathrm{dL}$ de $\mathrm{N}-\mathrm{NH}_{3}$ para maximização do consumo voluntário. Portanto, os valores encontrados neste trabalho suprem apenas o mínimo necessário para não limitar a atuação dos microrganismos ruminais.

\section{CONCLUSÕES}

A inoculação das silagens de milho com as duas cepas estudadas modificou a 


\section{INOCULAÇÃO DE SILAGENS DE MILHO COM LACTOBACILLUS}

composição química e o padrão fermentativo, estas mudanças não foram suficientes para alterar o consumo de matéria seca

\section{BIBLIOGRAFIA}

AOAC. 1996. Official Methods of Analysis, $16^{\text {th }}$ ed. Association of Official Analytical Chemists. Arlington, VA

Ashbell, G. and Weinberg, Z.G. 1992. Top silage losses in horizontal silos. Can J Chem Eng, 34: 171-175.

Barker, S.B. and Summerson, W.H. 1941. The colorimetric determination of lactic acid in biological material. J Biol Chem, 138: 535-554.

Bartolome, B.; Faulds, C.B.; Tuohy, M.; Hazlewood, G.P.; Gilbert, H.J. and Williamson, G. 1995. Influence of different xylanases on the activity of ferulic acid esterase of wheat bran. Biotechnol Appl Biochem, 22: 65-73.

Borreani, G.; Tabacco, E. and Cavallarin, L. 2007. A new oxygen barrier film reduces aerobic deterioration in farm-scale corn silage. $J$ Dairy Sci, 90: 4701-4706.

Butler, G.W. and Bailey, R.W. 1973. Chemistry and biochemistry of herbage. Acad. Press. London.

Casali, A.O.; Detmann, E.; Valadares Filho, S.C.; Pereira, J.C.; Henriques, L.T.; Freitas, S.G. e Paulino, M.F. 2008. Influência do tempo de incubação e do tamanho de partículas sobre os teores de compostos indigestíveis em alimentos e fezes bovinas obtidos por procedimentos in situ. Rev Bras Zootecn, 37: 335-342.

Contreras-Gouveia, F. and Muck, R. 2006. Microbial inoculants for silage. Focus on Forage, 8: 1-4.

Danner, H.; Holzer, M.; Mayrhuber, E. and Braun, R. 2003. Acetic acid increases stability of silage under aerobic conditions. Appl Environ Microb, 69: 562-567.

Detmann, E.; Paulino, M.F. e Valadares Filho, S.C. 2010. Otimização do uso de recursos forrageiros basais. Em: Simpósio de Produção de Gado de Corte, VII. Universidade Federal de Viçosa. Viçosa. pp. 191-240.

Donaghy, J.; Kelly, P.F. and McKay, A.M. 1998. Detection of ferulic acid esterase production by Bacillus spp. and Lactobacilli. Appl Microbiol Biot, 50: 257-260.

Driehuis, F.; Oude Elferink, S.J.W.H. and Spoelstra, S.F. 1999. Anaerobic lactic acid degradation e de nutrientes pelas novilhas mestiças, mas refletiram em maior digestibilidade aparente da matéria seca e matéria orgânica.

during ensilage of whole crop maize inoculated with Lactobacillus buchneri inhibits yeast growth and improves aerobic stability. J Appl Microbiol, 87: 583-594.

Famme, P. and Knudsen, J. 1984. Direct gas chromatographic determination of short - chain $\left(\mathrm{C}_{2}-\mathrm{C}_{4}\right)$ volatile fatty acids in aqueous solutions. Comp. Biochem Physiol, 77: 617-618.

Fenner, H. 1965. Method for determining total volatile bases in rumen fluid by stem distillation. J Dairy Sci, 48: 249-251.

Filya, I. 2003. The effect of Lactobacillus buchneri and Lactobacillus plantarum on the fermentation, aerobic stability, and ruminal degradability of low dry matter corn and sorghum silages. $J$ Dairy Sci, 86: 3575-3581.

Filya, I.; Sucu, E. and Karabulut, A. 2006. The effect of Lactobacillus buchneri on the fermentation, aerobic stability and ruminal degradability of maize silage. J Appl Microbiol, 101: 1216-1223.

Jobim, C.C.; Reis, R.A.; Schoken-Iturrino, R.P. e Rosa, B. 1999. Desenvolvimento de microrganismos durante a utilização de silagens de grãos úmidos de milho e de espigas de milho sem brácteas. Acta Sci, 21: 671-676.

Jobim, C.C.; Nussio, L.G.; Reis, R.A. e Schmidt, P. 2007. Avanços metodológicos na avaliação da qualidade da forragem conservada. Rev Bras Zootecn, 36: 101-119.

Kamarloiy, M. and Yansari, A.T. 2008. Effect of microbial inoculants on the nutritive value of corn silage for beef cattle. Pak J Biol Sci, 11: 1137-1141.

Kleinschmit, D.H.; Schmidt, R.J. and Kung Jr., L. 2005. The effects of various antifungal additives on the fermentation and aerobic stability of corn silage. J Dairy Sci, 88: 2130-2139.

Kung Jr., L. 2009. Effects of microbial additives in silages: facts and perspectives. In: M. Zopollatto G.B. Muraro and L.G. Nussio (Eds.). International Symposium on Forage Quality and Conservation. São Pedro. pp: 7-22.

Kung Jr., L.; Grieve, D.B.; Thomas, J.W. and Huber,

Archivos de zootecnia vol. 62, núm. 239, p. 389. 


\section{SALVO, BASSO, RABELO, OLIVEIRA, SADER, CASAGRANDE, BERCHIELLIE REIS}

J.T. 1984. Added ammonia or microbial inoculant for fermentation and nitrogenous compounds of alfalfa ensiled at various percents of dry matter. J Dairy Sci, 67: 299-306.

Kung Jr., L. and Muck, R.E. 1997. Animal response to silage additives. In: Silage: field to feedbunk. Northeast Regional Agricultural Engineering Service. Ithaca. pp. 200-210.

Kung Jr., L. and Ranjit, N.K. 2001. The effect of Lactobacillus buchneri and other additives on the fermentation and aerobic stability of barley silage. J Dairy Sci, 84: 1149-1155.

Kung Jr., L. and Shaver, R. 2001. Interpretation and use of silage fermentation analysis reports. Focus on Forage, 3: 1-5.

Kung Jr., L.; Stokes, M.R. and Lin, C.J. 2003a. Silage additives. In: D.R. Buxton, R.E. Muck and J.H. Harrison (Eds.). Silage science and technology. American Society Agronomy, Madison, WI. pp: 305-360.

Kung Jr., L.; Taylor, C.C.; Lynch, M.P. and Neylon, J.M. 2003b. The effect of treating alfafa with Lactobacillus buchneri 40788 on silage fermentation, aerobic stability, and nutritive value for lactating dairy cows. J Dairy Sci, 86: 336-343.

Leng, R.A. 1990. Factors affecting the utilization of 'poor-quality' forages by ruminants particularly under tropical conditions. Nutr Res Rev, 3: 277303.

McDonald, P.; Henderson, A.R. and Heron, S.J.E. 1991. The biochemistry of silage. Chalcomb Publications. Marlow, Bucks. UK. 340 pp.

Muck, R.E. 2010. Silage microbiology and its control through additives. Rev Bras Zootecn, 39: 183-191.

NRC. 2001. Nutrient requirements of dairy cattle. $7^{\text {th }}$ Rev. National Research Council. National Academy Press. Washington. $381 \mathrm{pp}$.

Oude Elferink, S.J.W.H.; Krooneman, J.; Gottschal,
J.C.; Spoelstra, S.F.; Faber, F. and Driehuis, F. 2001. Anaerobic conversion of lactic acid to acetic acid and 1,2 propanediol by Lactobacillus buchneri. Appl Environ Microbiol, 67: 125-132.

Reis, R.A.; Siqueira, G.R.; Roth, M.T.P. e Roth, A.P.T.P. 2008. Fatores que afetam o consumo de forragens conservadas. In: C.C. Jobim, U. Cecato e M.W. do Canto (Eds.). Produção e utilização de forragens conservadas. Masson, Maringá, PR. pp. 9-40.

SAS. 2008. Inc. Statistical analysis system. SAS Institute. Raleigh. North Carolina.

Sniffen, C.J.; O'Connor, J.D.; Van Soest, P.J.; Fox, D.G. and Russell J.B. 1992. A net carbohydrate and protein system for evaluating cattle diets: II. carbohydrate and protein availability. J Anim Sci, 70: 3562-3577.

Strobel, H.J. and Russell, J.B. 1986. Effect of pH and energy spilling on bacterial protein synthesis by carbohydrate limited cultures of mixed rumen bacteria. J Dairy Sci, 69: 2941-2947.

Van Soest, P.J.; Robertson, J.B. and Lewis, B.A. 1991. Methods for dietary fiber, neutral detergent fiber, and nonstarch polysaccharides in relation to animal nutrition. J Dairy Sci, 74: 3583-3597.

Van Soest, P.J. 1994. Nutritional ecology of the ruminant. $2^{\text {nd }}$ ed. Cornell University Press. Ithaca. $476 \mathrm{pp}$.

Weinberg, Z.G.; Muck, R.E.; Weimer, P.J.; Chen, Y. and Gamburg, M. 2004. Lactic acid bacteria used in inoculants for silage as probiotics for ruminants. Appl Biochem Biotech, 118: 1-9.

Wilson, R.K.A. 1971. A rapid accurate method for messureng volatile fatty acids and lactic acid in silage. Agricultural Institute. Dunsinea Research Centre. Dublin. 12 pp.

Yildirim, M. 2001. Purification of buchnericin LB produced by Lactobacillus buchneri LB. Turk J Biol, 25: 59-65. 